\title{
Detection of pagetoid urothelial intraepithelial neoplasia extending to the vagina by cervical screening cytology: a case report with renewed immunochemical summary
}

Yuki Koyanagi ${ }^{1 \dagger}$, Chiaki Kubo ${ }^{2 \dagger}$, Shigenori Nagata ${ }^{2 *}$ (D, Ayumi Ryu ${ }^{1}$, Koji Hatano ${ }^{3}$, Rieko Kano ${ }^{2}$, Satoshi Tanada ${ }^{1}$, Jun-ichi Ashimura', Atsushi Idota', Shoji Kamiura ${ }^{4}$, Tomoyuki Yamasaki ${ }^{1}$ and Shin-ichi Nakatsuka ${ }^{2}$

\begin{abstract}
Background: Pagetoid spread of urothelial carcinoma (UC) to the lower genital tract is quite a rare and diagnostically challenging condition. Pagetoid urothelial intraepithelial neoplasia extending to the vagina is difficult to diagnose, especially in remote recurrences without symptomatic or macroscopic lesions typical to Paget disease. However, its identification by cervical screening cytology is important because UC is often characterized by a long history of relapse.

Case presentation: A 68-year-old Japanese postmenopausal woman developed brown vaginal discharge after radical cystectomy for bladder cancer (high-grade UC, pT2a pNO CMO [Union for International Cancer Control, 8th edition]) concomitant with focal in-situ UC in the urethra. She had a history of left renal pelvis UC, which was surgically removed 9 months before the radical cystectomy. Gynecologic examination of the lower genital tract was unremarkable although cervical screening cytology demonstrated severely atypical cells with pleomorphism repeatedly. Cervical colposcopy and diagnostic conization revealed no cervical neoplasm. In retrospect, immunocytochemical p16/Ki-67 dual staining for the previous cervical screening was negative for p16 labeling, and the neoplastic cells were positive for cytokeratins 7 and 20, p63, and GATA binding protein 3. No high-risk human papillomavirus genotype was identified by an automated DNA chip system using liquid-based cytology samples. Eleven months post-cystectomy, punch biopsy of the vulva and vagina confirmed intraepithelial UC in the juxtaposed squamous epithelium with pagetoid spread demonstrating positivity for specific urothelial markers: uroplakins II and III and thrombomodulin. Concurrent invasive malignancy was ruled out, and $\mathrm{CO}_{2}$ laser vaporization of the vulvar and vaginal lesion was performed. The patient remained alive without evidence of invasive malignancy for 14 months after the radical cystectomy for bladder cancer.

(Continued on next page)
\end{abstract}

\footnotetext{
* Correspondence: nagata-si@mc.pref.osaka.jp

${ }^{\dagger}$ Yuki Koyanagi and Chiaki Kubo contributed equally to this work.

${ }^{2}$ Department of Diagnostic Pathology and Cytology, Osaka International

Cancer Institute Hospital, 3-1-69 Otemae, Chuo-ku, Osaka 541-8567, Japan

Full list of author information is available at the end of the article
}

C The Author(s). 2019 Open Access This article is distributed under the terms of the Creative Commons Attribution 4.0 International License (http://creativecommons.org/licenses/by/4.0/), which permits unrestricted use, distribution, and reproduction in any medium, provided you give appropriate credit to the original author(s) and the source, provide a link to the Creative Commons license, and indicate if changes were made. The Creative Commons Public Domain Dedication waiver (http://creativecommons.org/publicdomain/zero/1.0/) applies to the data made available in this article, unless otherwise stated. 
(Continued from previous page)

Conclusions: To detect recurrent pagetoid urothelial intraepithelial neoplasia with pagetoid spread in the lower genital tract, pathologists should recognize the history of prior UC with special attention to absence of p16 labeling in cervical cytology as a pointer to the diagnosis of urothelial cancer. Using further biopsy and immunohistochemical confirmation of UC relapse, investigation to rule out invasive malignancies and careful follow-up throughout the patient's lifetime is recommended.

Keywords: Pagetoid urothelial intraepithelial neoplasia, Secondary paget disease, Urothelial carcinoma, Bladder cancer, Lower genital tract, Vagina, GATA3, p16/Ki-67 double labeling, Cervical screening cytology, Liquid-

based cytology

\section{Background}

Extensive urothelial carcinoma (UC) involves various organs along the urinary tract and often has a long history of relapse [1]. Pagetoid spread of UC to the lower genital tract is rare and difficult to diagnose, especially in remote recurrences without apparent macroscopic lesions. We describe a case of metachronous UC with pagetoid spread to the vagina, which was diagnosed by cervical cytology and vaginal biopsy, and herein summarize the clinicopathologic differences among Paget-like neoplasms of the lower genital tract with recent immunocytochemical/immunohistochemical markers.

\section{Case presentation Clinical course}

A 68-year-old Japanese postmenopausal woman developed brown vaginal discharge after radical cystectomy for bladder cancer, which was histologically diagnosed as high-grade UC invading up to the superficial muscularis propria without metastasis (pT2a pN0 cM0 [Union for International Cancer Control, 8th edition]) concomitant with focal urothelial carcinoma in situ in the urethra. She had a history of left renal pelvis UC, which was surgically removed after repeated $80-\mathrm{mg} /$ fraction Bacillus Calmette-Guérin injections via a single J stent, resulting in no residual carcinoma 9 months before the radical cystectomy. She was also treated for breast cancer at 47 years of age without postoperative recurrence. Gynecologic examination of the lower genital tract, including the periurethral region, was unremarkable; however, cervical screening cytology demonstrated severely atypical cells suspicious for adenocarcinoma (Fig. 1a-c). Cervical colposcopy and diagnostic conization revealed no cervical neoplasm. Eleven months post-cystectomy, punch biopsy of the vulva and vagina confirmed intraepithelial UC in the juxtaposed squamous epithelium with pagetoid spread (Fig. 2a-c). Concurrent invasive malignancy was ruled out, and $\mathrm{CO}_{2}$ laser vaporization of the vulvar and vaginal lesion was performed. The patient remained alive without evidence of invasive malignancy for 14 months after the radical cystectomy for bladder cancer.

\section{Immunocytochemical and immunohistochemical analyses and human papillomavirus test}

The CINtec ${ }^{\oplus}$ PLUS cytology test (Roche Diagnostics, Basel, Switzerland), an immunocytochemical p16/Ki-67 dual staining kit for screening of cervical disease, was negative for p16 labeling (Fig. 1d). Immunocytochemistry revealed neoplastic cells positive for cytokeratin (CK) 7, CK20, p63, and GATA3 (Fig. 1e-h). Immunohistochemical examination of the biopsy sample of the vulva and vagina revealed neoplastic cells positive for uroplakin III, thrombomodulin, and uroplakin II (Fig. 2d-f) but negative for carcinoembryonic antigen (CEA), gross cystic disease fluid protein 15 (GCDFP15), and S100. No high-risk human papillomavirus (HPV) genotype was identified by an automated DNA chip system (Clinichip ${ }^{\mathrm{TM}}$ HPV test; Sekisui Medical, Tokyo, Japan) using LBC samples.

\section{Discussion}

Female genital organs can be synchronously or metachronously involved in bladder cancer, with vaginal involvement predominating. Recently, Salem et al. reported on 360 women who underwent radical cystectomy for bladder cancer, of which 13 (3.6\%) had vaginal involvement and 1 had uterine spread [2]. Similarly, Djaladat et al. found vaginal involvement in at least 10 (3.7\%) of 267 women who underwent cystectomy with reproductive organ removal [3]. Although the morphologic pattern of vaginal involvement is unclear in those studies, pagetoid spread of UC is considered much rarer; Gregori et al. reported that only 2 of 98 cases of vulvar Paget disease were related to bladder UC [4]. In the present case, biopsy revealed both the vulvar and vaginal involvement by UC whereas there was no evidence of uterine involvement in the specimen of cervical conization. 


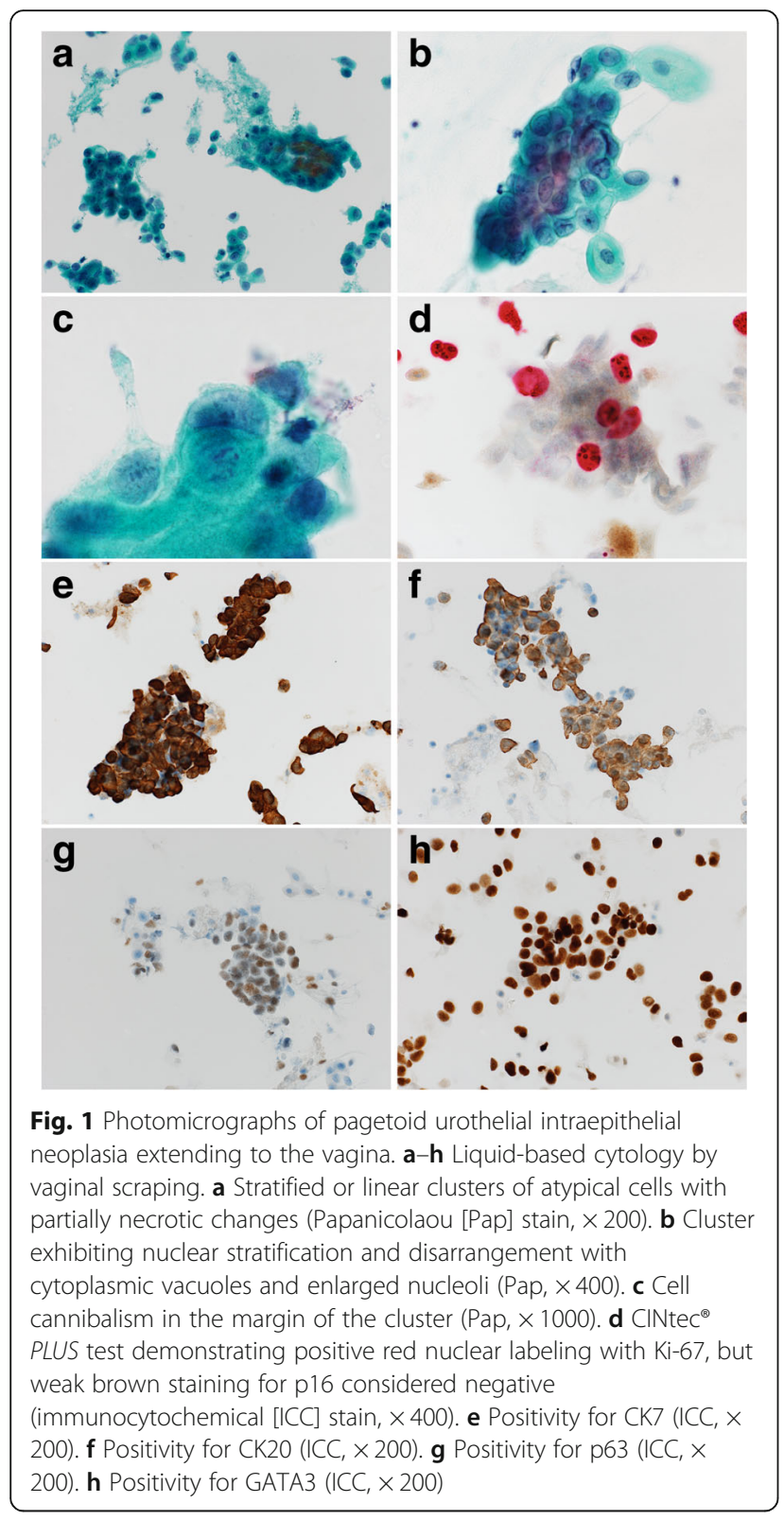

Pagetoid spread of carcinoma is characterized by proliferation of individual or clustered tumor cells in the lower part of the juxtaposed squamous epithelium. Vulvar pagetoid neoplasm of urothelial origin is the secondary, noncutaneous type of extramammary Paget disease, which was termed pagetoid urothelial intraepithelial neoplasia by Wilkinson and Brown [5]. Pagetoid urothelial intraepithelial neoplasia can involve the vagina, uterine cervix, and rarely the endometrium [6]. Although primary and secondary types of Paget disease have overlapping clinical presentations, histologic distinction is usually straightforward; the former is characterized by Paget cells with abundant pale cytoplasm with rare mitoses, while the latter usually displays severe disarrangement of neoplastic cells with mitotic activity often showing pleomorphism/anaplasia [6] (Table 1). However, to avoid diagnostic challenges, diagnosis of pagetoid urothelial intraepithelial neoplasia often requires detection of specific markers of urothelial differentiation. UC typically shows positivity for high-molecular-weight $\mathrm{CK}$ and p63 with coexpression of CK7 and CK20 in 50 to $80 \%$ of cases [7]. Both uroplakin III and thrombomodulin are highly specific to UC [7], and a newer marker, uroplakin II (clone BC21), demonstrates improved sensitivity (around $80 \%$ ) and positive intensity compared with uroplakin III [8]. While a panel of these antibodies is generally sufficient for differential diagnosis, the history of prior UC provides the most important diagnostic clue for pagetoid urothelial intraepithelial neoplasia.

LBC has recently been widely applied to various samples with subsequent immunocytochemistry as a useful diagnostic tool. In the present case, the absence of p16 labeling on $\mathrm{CINtec}^{\circ}$ PLUS with positivity for GATA3 led the pathologist to suspect pagetoid urothelial intraepithelial neoplasia, which was confirmed upon obtaining the clinical history. However, careful attention is needed when using these two relatively new markers because UC must be discriminated from mimics (Table 1). Piaton et al. investigated p16/Ki-67 dual labeling in urinary cytology and found p16 positivity in 93 (93.9\%) of 99 high-grade urothelial cells, among which coexpression of p16/Ki-67 in the same cells was noted in 80 (79.2\%) of 101 high-grade tumors [9]. It is noted that the weak p16 staining is usually considered negative. GATA3 is not useful for distinguishing pagetoid urothelial intraepithelial neoplasia from primary extramammary Paget disease; Zhao et al. recently reported that almost all 72 cases of primary vulvar Paget disease were positive for GATA3 [10]. However, GATA3 is helpful to exclude either secondary Paget disease of colorectal origin or high-risk HPV-associated neoplasm [11, 12]. Therefore, to ensure the diagnosis of pagetoid urothelial intraepithelial neoplasia, adenocarcinoma must be excluded using reliable markers such as CEA and GCDFP15 in addition to specific high-risk HPV detection in cervical cytology.

\section{Conclusions}

In summary, we have presented an unusual case of pagetoid urothelial intraepithelial neoplasia with extension to the vagina in a woman who underwent left nephroureterectomy and subsequent radical 

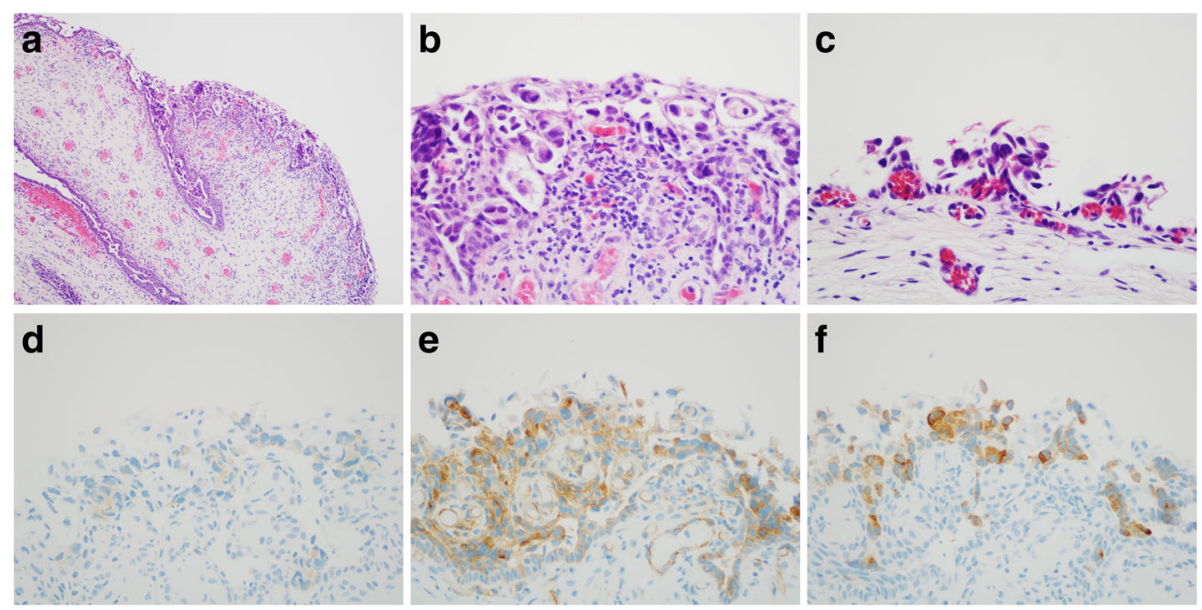

Fig. 2 Photomicrographs of pagetoid urothelial intraepithelial neoplasia extending to the vagina. a-f Punch biopsies from the vulva and anterior vaginal wall. a Large cells proliferating within the basal and parabasal layers of the vulvar squamous epithelium (hematoxylin and eosin [HE] stain, $\times 10$ ). $\mathbf{b}$ Paget-like cells with larger nuclei and paler cytoplasm than the adjacent keratinocytes about clefts, an apparent artifact that is a common finding in pagetoid urothelial intraepithelial neoplasia $(\mathrm{HE}, \times 400)$. c Similar cells of high nuclear grade identified in the mostly denuded vagina $(H E, \times 400)$. d Focal positivity for uroplakin III (immunohistochemical $[\mathrm{IHC}]$ stain, $\times 400)$. e Positivity for thrombomodulin $(\mathrm{IHC}, \times 400)$. f Positivity for uroplakin II $(I \mathrm{HC}, \times 400)$

cystectomy for metachronous UC, highlighting LBC with immunocytochemical pitfalls. Pagetoid urothelial intraepithelial neoplasia of the lower genital tract is difficult to diagnose without symptomatic lesions typical to Paget disease, such as pruritic eczema in the vulvar vestibule and/or periurethral region. Pathologists should nevertheless consider remote recurrence of UC in cervical cytology with special attention to absence of p16 labeling despite high-grade morphology as a pointer to the diagnosis of urothelial cancer. Using further biopsy and immunohistochemical confirmation of UC relapse, investigation to rule out invasive malignancies and careful follow-up throughout the patient's lifetime is recommended.

Table 1 Clinicopathologic and laboratory differences between Paget-like neoplasms and mimics of the lower genital tract

\begin{tabular}{|c|c|c|c|c|}
\hline & $\begin{array}{l}\text { Extramammary/vulvar } \\
\text { Paget disease }\end{array}$ & Pagetoid urothelial carcinoma & $\begin{array}{l}\text { Pagetoid colorectal } \\
\text { carcinoma }\end{array}$ & $\begin{array}{l}\text { High-risk HPV-associated } \\
\text { neoplasm }\end{array}$ \\
\hline History & Not characterized & Prior urinary tract neoplasm & $\begin{array}{l}\text { Prior anorectal } \\
\text { neoplasm }\end{array}$ & $\begin{array}{l}\text { Atypical squamous/glandular } \\
\text { cells in screening cytology }\end{array}$ \\
\hline $\begin{array}{l}\text { Cell } \\
\text { morphology }\end{array}$ & $\begin{array}{l}\text { Paget cells characterized by } \\
\text { abundant pale cytoplasm and } \\
\text { prominent nucleoli with rare mitoses }\end{array}$ & $\begin{array}{l}\text { Highly stratified/disarranged or } \\
\text { pleomorphic/anaplastic cells } \\
\text { with mitotic activity }\end{array}$ & $\begin{array}{l}\text { Colonic type cells with } \\
\text { intracytoplasmic mucin } \\
\text { and goblet cells }\end{array}$ & $\begin{array}{l}\text { Cells indicating high-grade } \\
\text { squamous/glandular intraepithelial } \\
\text { lesion or their invasive forms }\end{array}$ \\
\hline \multicolumn{5}{|c|}{ Immunochemical markers } \\
\hline $\begin{array}{l}\text { Typically } \\
\text { positive }\end{array}$ & $\begin{array}{l}\text { CK7, CAM5.2, GCDFP15, CEA, } \\
\text { CA125, HER2/neu, androgen } \\
\text { receptor }\end{array}$ & $\begin{array}{l}\text { CKs } 7 \text { and } 20 \text { (co-expression), } \\
\text { p63, HMWCK, uroplakins II and } \\
\text { III, thrombomodulin }\end{array}$ & CK20, CEA, CDX2, MUC2 & $\begin{array}{l}\text { p40, p63, HMWCK (squamous } \\
\text { neoplasm); CK7, CEA (glandular } \\
\text { neoplasm) }\end{array}$ \\
\hline $\begin{array}{l}\text { Typically } \\
\text { negative }\end{array}$ & CK20, ER, PgR & GCDFP15, CEA & CK7, GCDFP15 & CK20, GCDFP15 \\
\hline $\begin{array}{l}\text { p16/Ki-67 } \\
\text { double } \\
\text { labeling }\end{array}$ & Unknown & Usually positiveRef \#9 & Unknown & Positive \\
\hline GATA3 & PositiveRef \#10 & Usually positiveRef \#11 & NegativeRef \#11 & $\begin{array}{l}\text { Usually negative, but occasionally } \\
\text { weakly positiveRef } \# 12\end{array}$ \\
\hline HPV test & Negative & Negative & Negative & High-risk genotypes detected \\
\hline
\end{tabular}

HPV human papillomavirus, $C K$ cytokeratin, ER estrogen receptor, $P g R$ progesterone receptor, GCDFP15 gross cystic disease fluid protein $15, C E A$ carcinoembryonic antigen, HER2 human epidermal growth factor receptor 2, HMWCK high-molecular-weight cytokeratin, MUC2 mucin 2, GATA3 GATA binding protein 3, Ref reference article 


\section{Abbreviations}

CEA: Carcinoembryonic antigen; CK: Cytokeratin; GATA3: GATA binding protein 3; GCDFP15: Gross cystic disease fluid protein 15; HPV: Human papillomavirus; LBC: Liquid-based cytology; UC: Urothelial carcinoma

\section{Acknowledgements}

We are indebted to Dr. Hiroaki Fushimi, Department of Pathology, Osaka General Medical Center, for contributing to the immunohistochemical analysis. We also thank Angela Morben, DVM, ELS, from Edanz Group (https://www.edanzediting.com/), for editing a draft of this manuscript.

\section{Funding}

Not applicable.

\section{Availability of data and materials}

The datasets used and/or analyzed during the current study are available from the corresponding author upon reasonable request.

\section{Authors' contributions}

YK, CK, SN (corresponding author): conception, pathologic diagnosis, and writing of manuscript. AR, ST, JA: cytologic diagnosis and immunocytochemical analysis. KH, RK, SK: collection of clinical data. Al, TY, SN (the last author): revision of manuscript. All authors read and approved the final manuscript prior to submission.

\section{Ethics approval and consent to participate}

Not applicable.

\section{Consent for publication}

Written informed consent was obtained from the patient for the publication of this case report. A copy of the consent form is available for review by the Editor of this journal.

\section{Competing interests}

The authors declare that they have no competing interests.

\section{Publisher's Note}

Springer Nature remains neutral with regard to jurisdictional claims in published maps and institutional affiliations.

\section{Author details}

'Department of Clinical Laboratory, Osaka International Cancer Institute Hospital, Osaka, Japan. 'Department of Diagnostic Pathology and Cytology, Osaka International Cancer Institute Hospital, 3-1-69 Otemae, Chuo-ku, Osaka 541-8567, Japan. ${ }^{3}$ Department of Urology, Osaka International Cancer Institute Hospital, Osaka, Japan. ${ }^{4}$ Department of Gynecologic Oncology, Osaka International Cancer Institute Hospital, Osaka, Japan.

Received: 5 November 2018 Accepted: 24 January 2019

Published online: 02 February 2019

\section{References}

1. Kishi K, Hirota T, Matsumoto K, Kakizoe T, Murase T, Fujita J. Carcinoma of the bladder: a clinical and pathological analysis of 87 autopsy cases. J Urol. 1981;125:36-9

2. Salem H, El-Mazny A. Primary and secondary malignant involvement of gynaecological organs at radical cystectomy for bladder cancer: review of literature and retrospective analysis of 360 cases. J Obstet Gynaecol. 2012; 32:590-3.

3. Djaladat H, Bruins HM, Miranda G, Cai J, Skinner EC, Daneshmand S. Reproductive organ involvement in female patients undergoing radical cystectomy for urothelial bladder cancer. J Urol. 2012;188(6):2134-8.

4. Gregori CA, Smith Cl, Breen JL. Extramammary Paget's disease. Clin Obstet Gynecol. 1978;21(4):1107-15.

5. Wilkinson EJ, Brown HM. Vulvar Paget disease of urothelial origin: a report of three cases and a proposed classification of vulvar Paget disease. Hum Pathol. 2002:33(5):549-54.

6. Reyes MC, Park KJ, Lin O, loffe O, Isacson C, Soslow RA, et al. Urothelial carcinoma involving the gynecologic tract: a morphologic and immunohistochemical study of 6 cases. Am J Surg Pathol. 2012;36(7):1058-65.
7. Parker DC, Folpe AL, Bell J, Oliva E, Young RH, Cohen C, et al. Potential utility of uroplakin III, thrombomodulin, high molecular weight cytokeratin, and cytokeratin 20 in noninvasive, invasive, and metastatic urothelial (transitional cell) carcinomas. Am J Surg Pathol. 2003;27(1):1-10.

8. Hoang LL, Tacha DE, Qi W, Yu C, Bremer RE, Chu J, et al. A newly developed uroplakin II antibody with increased sensitivity in urothelial carcinoma of the bladder. Arch Pathol Lab Med. 2014;138(7):943-9.

9. Piaton $E$, Carré $C$, Advenier AS, Decaussin-Petrucci M, Mège-Lechevallier F, Lantier $\mathrm{P}$, et al. p16 INK4a overexpression and p16/Ki-67 dual labeling versus conventional urinary cytology in the evaluation of urothelial carcinoma. Cancer Cytopathol. 2014;122(3):211-20.

10. Zhao M, Zhou L, Sun L, Song $Y$, Guo $Y$, Zhang $X$, et al. GATA3 is a sensitive marker for primary genital extramammary paget disease: an immunohistochemical study of 72 cases with comparison to gross cystic disease fluid protein 15. Diagn Pathol. 2017:12(1):51.

11. Miettinen M, McCue PA, Sarlomo-Rikala M, Rys J, Czapiewski P, Wazny K, et al. GATA3: a multispecific but potentially useful marker in surgical pathology: a systematic analysis of 2500 epithelial and nonepithelial tumors. Am J Surg Pathol. 2014;38(1):13-22.

12. Schwartz LE, Khani F, Bishop JA, Vang R, Epstein Jl. Carcinoma of the uterine cervix involving the genitourinary tract: a potential diagnostic dilemma. Am J Surg Pathol. 2016:40(1):27-35.

\section{Ready to submit your research? Choose BMC and benefit from:}

- fast, convenient online submission

- thorough peer review by experienced researchers in your field

- rapid publication on acceptance

- support for research data, including large and complex data types

- gold Open Access which fosters wider collaboration and increased citations

- maximum visibility for your research: over $100 \mathrm{M}$ website views per year

At BMC, research is always in progress.

Learn more biomedcentral.com/submissions 